\title{
BREASTFEEDING AND TIME OF COMPLEMENTARY FOOD INTRODUCTION AS PREDICTORS OF OBESITY IN CHILDREN
}

\author{
Mariana Turčić Škledar', Milan Milošević \\ ${ }^{1}$ Department of School and University Medicine, National Public Health Institute for Zagreb County, Zaprešić, Croatia \\ ${ }^{2}$ Department for Environmental and Occupational Health, Andrija Stampar School of Public Health, School of Medicine, University of Zagreb, \\ Zagreb, Croatia
}

\begin{abstract}
SUMMARY
Although obesity is a multifactorial disorder caused by various behavioural, genetic and environmental influences, early life factors affecting certain critical periods during childhood (prenatal period, adiposity rebound period at 3-5 years and around 5-7 years, as well as puberty) are important in promoting obesity in adulthood. The objective was to determine the association between the birth weight, birth length, breastfeeding and time of introduction of complementary food with obesity among 302 healthy Caucasian children 6-7 years old. Binary logistic regression analysis was used to assess the impact of a number of perinatal and socioeconomic confounding factors on the likelihood for overweight and obesity among children. The level of significance was set at $p<0.05$. Our findings indicate that duration of breastfeeding for at least 3 months, with introduction of complementary food after the age of 6 months have an important role in preventing obesity. This findings are crucial for planning preventive strategies to prevent further increases in the prevalence of overweight and obesity.
\end{abstract}

Key words: children, obesity, breastfeeding duration, introduction of complementary food, body mass index centile charts

Address for correspondence: M. Turčić Škledar, National Public Health Institute for Zagreb County, Department of School and University Medicine, Mokrička ulica 54, p.p.34, 10290 Zaprešić, Croatia. E-mail: turcic.m.ri@gmail.com

\section{INTRODUCTION}

Nowadays, about 22 million 5-year-old children are obese worldwide, with rapid rises in prevalence that is now considered to be at epidemic level in developed as well as in developing coutries. Moreover, the number of overweight children in the European Union is expected to enlarge up to 1.3 million children per year (1). Its association with cardiovascular, endocrine, gastrointestinal, orthopaedic and respiratory diseases, but also with all kinds of psychological problems, implies a problem of far-reaching consequences for health and health services. There are certain periods during childhood that are proposed to be critical for later development of obesity: prenatal period, adiposity rebound period around 5-7 years of age, and puberty (2). Unless one or both of the parents suffer from obesity, increases in body mass index (BMI) prior to 3 years of age are weakly associated with adult obesity, but after this age the probability of being obese later in life rises with age and the level of obesity. After the age of 6 , this probability rises up to $50 \%$, while over $70-80 \%$ of obese adolescents remain obese in adulthood (3). Obviously, prevention of childhood obesity during the pre-school period could be crutial for preventing obesity later in life.

High birth weight, rapid infancy weight gain, firstborn children and being an only child, low socioeconomic status, lower level of parental education, and maternal smoking during pregnancy are considered independent risk factors for later obesity (4), although their interaction cannot be excluded as well as the influence of nutrition status on those confounders. In fact, infant weight gain directly depends on the type of nutrition that can later affect both body composition and BMI in children and adolescents because of possible changes in hormonal status (5).

Biological mechanisms underlying the protective effect of breastfeeding are based on metabolic responses to human milk and its unique composition. Breastfed infants have lower plasma insulin levels, preventing excessive early adipocyte development and decreasing fat storage. Also, bioactive factors contained in breast milk inhibit adipocyte differentiation in vitro by modulating tumor necrosis factor and epidermal growth factor (6). Furthermore, protein intake and the amount of metabolized energy in breastfed infants have been shown to be substantially below the amounts of formula-fed children resulting in slower infant growth that points to its fundamental role in later development of overweight and obesity (7). For that reason breastfeeding, because of its plausible biological mechanisms, apart from contributing to childrens health, is considered as a potential priming factor against overweight, obesity and other related diseases (5). Nevertheless, available literature on this matter is stil controversial and inconsistent. Some of the studies indicate significant protective effect of breastfeeding for at least the first 3 months on later obesity, especially in adolescence (8-11), while others found no influence of breastfeeding or dose-dependent effect on mean BMI (12-14). Unfortunatelly, most of those studies failed to adjust their resaerch for confounders associated with breastfeeding, which may contribute to inconsistent results (15). On the other hand, though late introduction of complementary food, also related to longer duration of breastfeeding, is considered as a potential priming factor against overweight, obesity and other related diseases in children (10), there are a number of reports showing that this difference in 
weight gain ceases to exist after the age of 18 months $(16,17)$. Thus, whereas the time of complementary food introduction has a feasible effect on childhood obesity still remains unclear.

Since one third of obese pre-school and half of obese school children remain obese in adulthood, early prevention and health promotion interventions are relevant, not only in a view of lowering healthcare costs and social risks that obese children are exposed to, but also in order to reduce the large number of overweight and obese in adult population, whilst it would as well contribute to decreasing morbidity and mortality in adult age (18).

The objective of this study was to determine whether childhood overweight and obesity is associated with the occurrence and duration of breastfeeding or the time when complementary foods are introduced. Likewise, we wanted to determine whether higher birth weight or/and birth length implicate higher BMI in healthy Caucasian children 6-7 years old, of specific geographic area and similar socioeconomic, cultural, educational, and familial influences.

\section{MATERIALS AND METHODS}

The study included 302 healthy Caucasian children of Croatian origin enrolled in the first year of grammar public scools from Saint John Zelina and Vrbovec, Zagreb County, within the period of 2002-2006. The relevant information was collected from paediatric and our preventive care records. The existence of any mental or physical disorders among participants that would require medical intervention or therapy was excluded. All measurements were gained by physician during regular medical exam using standard techniques and with closely monitored quality of the collected data. In addition, from original 316 examined children we excluded 14 preterm births $(<37$ week of gestation) and restricted our sample to children born at term (37-42 weeks of gestation). Height, in centimeters ( $\mathrm{cm})$, was measured in standing position, using a fixed tape meter to the nearest $0.5 \mathrm{~cm}$. Body weight, in kilograms $(\mathrm{kg})$, was measured without shoes and with light clothing (underpants and undershirt), using an analogue Seca Scale. BMI measures were also calculated using the formula $\mathrm{kg} /$ $\mathrm{m}^{2}$. According to children's length at birth boys and girls were categorized into 2 groups, normal size $(48-52 \mathrm{~cm})$ and big size newborns $(>52 \mathrm{~cm})$. In addition, chidren were classified as normal weight $(2,500-4,000 \mathrm{~g})$ and overweight newborns $(>4,000 \mathrm{~g})$. Cut off points for overweight and obesity in children were determined by body mass index with underweight children defined as below the 5 th percentile, normal weight between the 5 th and 85 th percentile, overweight between the 85 th and 95 th percentile, and obese as above the 95 th percentile. The prevalence of overweight and obesity was defined using standard BMI-for-age growth charts that are used in practice in accordance with the reference of Centres for Disease Control and Prevention (CDC) and Croatian Society for Paediatric Endocrinology. Prior to starting the study, permission from the local Ethic Commission was obtained and the study was conducted in compliance with all ethical criteria.

The analysis of variance (ANOVA), Kruskal-Wallis test, Chi-square test, Fisher test, Student t-test, and Mann Whitney $\mathrm{U}$ test were used to test the differences considering the duration of breastfeeding, sex, birth weight and birth length. The level of significance was set at $\mathrm{p}<0.05$.
Binary logistic regression was performed to assess the impact of a number of factors on the likelihood of overweight and obesity among children. The model comprised 12 independent variables (gender, age, marriage, parents' education, number of siblings, delivery type, birth weight and length, additional milk formula and complementary food introduction, breast-feeding duration). The full model was statistically significant $(\mathrm{p}=0.001)$, indicating that it distinguished between children who are overweight and obese compared to those who are not.

\section{RESULTS}

After the exclusion of 14 preterm born children, the analysed sample comprised 302 children with complete data on infant feeding, sex, anthropometric measures and corresponding age, and potential confounders. The final sample consisted of 146 boys (48.34\%) and 156 girls (51.66\%). Out of 302 children, $13.3 \%$ of boys and $12.7 \%$ of girls were overweight ( $85-95$ centile), while there were $23.3 \%$ of obese boys and $13.3 \%$ of obese girls ( $>95$ centile) according to standard BMI-for-age growth charts.

Although we had more obese boys than girls among our participants, those differences were not statistically significant. Hence, there were no variation in prevalence of overwieight and obesity among genders $\left(\chi^{2}=5.579, \mathrm{DF}=2, \mathrm{p}=0.061\right)$.

Besides the above mentioned, when the prevalence of overweight and obese children was calculated, $36.7 \%$ of boys and $25.9 \%$ of girls were at or above the 85 th percentile. Differences were also found in prevalence of normal weight and overweight children according to gender (Fisher exact probability test, $\mathrm{DF}=1$, $\mathrm{p}=0.049$, Phi $=0.116$ ).

BMI distribution differs significantly from normal distribution (Kolmogorov-Smirnov, $\mathrm{p}<0.001$ ). Nevertheless, we found no distinction in BMI among boys and girls (Mann Whitney $\mathrm{U}=10,556.0 ; \mathrm{Z}=-1.656 ; \mathrm{p}=0.101)$. BMI median for boys was 16.3 (interquartile range: $15.0-18.3$ ) and for girls 15.9 (interquartile range: $14.7-17.3)$.

We observed no sex differences in birth weight (boys: 3,455 g; IQR: 3,100-3,770; girls: 3,310 g; IQR: 3,007-3,693/Mann Whitney $U=10,500.0 ; Z=-1.728 ; p=0.083)$. Still, there was a significant sex difference in birth length in favour of boys (Mann Whitney $U=10,176.0 ; Z=-2.169 ; p=0.031)$. Birth length median in boys was $51 \mathrm{~cm}$ (IQR: 49-52) and $50 \mathrm{~cm}$ in girls (IQR: 49-52).

There were no differences in duration of breastfeeding among genders (Mann Whitney $U=11,662.5 ; Z=-0.241 ; p=0.808$ ). Median of breastfeeding duration for boys was 5.5 months (IQR: 1.4-9) and for girls 5.0 months (IQR: 1-12).

We found no significant relations between BMI and birth length or the duration of breastfeeding (Table 1). Significant difference in birth weight was observed between normal weight and obese children $(p=0.017)$, but not in overweight children. Further, no significant difference was found in nutrition status of children when number of siblings was considered.

The regression model as a whole explained between 13.2\% (Cox and Snell R square) and 18.5\% (Nagelkerke R squared) of the variance in overweight/obesity status, and correctly classified $70.5 \%$ of cases. As shown in Table 2, two of the independent variables made a unique statistically significant contribution to the model: use of additional formula before third month $(\mathrm{OR}=3.35$, 
Table 1. Comparison of birth weight, birth length and the duration of breastfeeding and BMI according to standard BMI-for-age growth charts $(N=302)$

\begin{tabular}{|l|c|c|c|c|c|c|}
\hline & \multicolumn{3}{|c|}{ Children weight status } & \multicolumn{3}{c|}{ Test results } \\
\cline { 2 - 7 } & $\begin{array}{c}\text { Normal weight } \\
\mathrm{n}=205\end{array}$ & $\begin{array}{c}\text { Overweight } \\
\mathrm{n}=43\end{array}$ & $\begin{array}{c}\text { Obese } \\
\mathrm{n}=54\end{array}$ & \multicolumn{2}{c|}{$\mathrm{df}=2$} & $\mathrm{p}<0.001$ \\
\hline Birth weight (g): mean $\pm \mathrm{SD}^{*}$ & $3,332 \pm 482.4$ & $3,516.5 \pm 483.7$ & $3,603.15 \pm 472.5$ & $\mathrm{~F}=8.10$ & $\mathrm{df}=2$ & $\mathrm{p}=0.006$ \\
\hline Birth length (cm): mean $\pm \mathrm{SD}^{*}$ & $50.2 \pm 2.3$ & $50.9 \pm 1.9$ & $51.2 \pm 2.2$ & $\mathrm{f}=5.23$ & $\mathrm{df}=2$ & $\mathrm{p}=0.136$ \\
\hline $\begin{array}{l}\text { Duration of breastfeeding } \\
\text { (months): median (interquartile } \\
\text { range** }\end{array}$ & $6.0(1.5-12.0)$ & $5.0(1.4-7.0)$ & $3.0(1.0-9.0)$ & $X^{2}=3.99$ & & \\
\hline
\end{tabular}

${ }^{*}$ One-Way ANOVA

${ }^{* *}$ Kruskal-Wallis test

Table 2. Predictors for overweight and obesity among children according to standard centiles: binary logistic regression

\begin{tabular}{|c|c|c|c|c|c|c|c|c|}
\hline \multirow{2}{*}{ Predictors } & \multirow{2}{*}{ B } & \multirow{2}{*}{ S.E. } & \multirow{2}{*}{ Wald } & \multirow{2}{*}{ df } & \multirow{2}{*}{ OR } & \multicolumn{2}{|c|}{$95 \% \mathrm{Cl}$} & \multirow{2}{*}{$\mathrm{p}$} \\
\hline & & & & & & Lower & Upper & \\
\hline Female gender & -0.20 & 0.28 & 0.54 & 1 & 0.82 & 0.48 & 1.40 & 0.463 \\
\hline Age & -0.6 & 0.35 & 2.81 & 1 & 0.56 & 0.28 & 1.10 & 0.094 \\
\hline Caesarean section & -0.03 & 0.41 & 0.01 & 1 & 0.97 & 0.43 & 2.18 & 0.943 \\
\hline Birth weight (g) & 0.00 & 0.00 & 4.39 & 1 & 1.00 & 1.00 & 1.00 & 0.036 \\
\hline Birth length $(\mathrm{cm})$ & 0.10 & 0.09 & 1.31 & 1 & 1.10 & 0.93 & 1.30 & 0.252 \\
\hline Breast-feeding duration (months) & 0.37 & 0.21 & 3.06 & 1 & 1.45 & 0.96 & 2.20 & 0.080 \\
\hline Without additional formula (ref.) & & & 7.36 & 3 & & & & 0.061 \\
\hline$<3$ months & 1.21 & 0.48 & 6.35 & 1 & 3.35 & 1.31 & 8.60 & 0.012 \\
\hline $3-6$ months & 0.79 & 0.42 & 3.59 & 1 & 2.21 & 0.97 & 5.01 & 0.058 \\
\hline$>6$ months & 0.02 & 1.21 & 0.00 & 1 & 1.02 & 0.10 & 10.91 & 0.986 \\
\hline Complementary food $<6$ months & 0.90 & 0.32 & 8.10 & 1 & 2.46 & 1.32 & 4.58 & 0.004 \\
\hline Without siblings (ref.) & & & 0.37 & 2 & & & & 0.830 \\
\hline One sibling & 0.15 & 0.55 & 0.07 & 1 & 1.16 & 0.39 & 3.42 & 0.786 \\
\hline More than one & -0.03 & 0.57 & 0.00 & 1 & 0.98 & 0.32 & 2.95 & 0.964 \\
\hline Father education & -0.04 & 0.32 & 0.02 & 1 & 0.96 & 0.51 & 1.81 & 0.896 \\
\hline Mother education & 0.22 & 0.29 & 0.55 & 1 & 1.24 & 0.70 & 2.20 & 0.457 \\
\hline Divorced & 0.03 & 0.58 & 0.00 & 1 & 1.03 & 0.33 & 3.23 & 0.959 \\
\hline
\end{tabular}

S.E. $=$ standard error, $B=B$ coefficient, $d f=$ degrees of freedom, $\mathrm{OR}=$ odds ratio, ref. $=$ referent value

95\% CI: $1.31-8.60 ; \mathrm{p}=0.012)$ and complementary food introduction before sixth month $(\mathrm{OR}=2.46,95 \% \mathrm{CI}: 1.32-4.58 ; \mathrm{p}=0.004)$.

This indicates that children who are on formula before third month and on supplementation before sixth month are respectively 3.35 times and 2.46 times more likely to become overweight/ obese, controlled for all other factors in the model.

\section{DISCUSSION}

Our findings indicate that duration of breastfeeding for at least 3 months, with introduction of complementary food after the age of 6 months have an important role in preventing obesity.

The prevalence of obesity in 6-7 years old children was not gender associated, that is in line with several other studies where the possible effect of gender was excluded at that age $(19,20)$. Although in the research of adolescents of Brazil origin significant positive association of birth weight and obesity was detected even after adjustment for confounding factors (21), association between high birth weight and overweight among our participants abolished after adjustment for confounders in binary logistic regression model, that is also in conformity with prior published systematic review (15).

Although beneficial effects of breast milk are well known suggesting its protective role in reduction of later overweight and obesity (6-7), a number of reported studies failed to confirm the protective effect of breastfeeding against obesity in children (22-27), that is consistent with our finding when breastfeeding was considered as an independent factor. Nevertheless, when controlled for all other confounding factors, we observed that children who are on formula before third month and on supplementation before sixth month are respectively 3.35 times and 2.46 times more likely to become overweight/obese, indicating protective effect of breastfeeding in infants breastfed for 3 months or more. Majority of authors report similar results about protective effect of breastfeeding in infants breastfed for 
3 months or more regardless of timing of introduction of infant formula or complementary food, indicating time-dependent association between duration of breastfeeding and obesity $(9,10$, $28,29)$. Recent systematic review of all relevant studies and meta-analyses suggests that breastfeeding is associated with a modest risk reduction of later obesity, explaining these apparently equivocal results by different effects of breastfeeding in normal weight compared with overveight and obese children. Inconsistent results may emerge from the use of inadequate methodology standards, large number of residual, unmeasured or unknown confounders, cumulative effects, publication bias, potentional heterogeneity between studies, recall bias, the lack of long-term follow-up, and the contribution of parental genes that is almost impossible to resolve (15). Most relevant confounders associated with breastfeeding are maternal BMI, education and smoking during pregnancy, socioeconomic and cultural factors, gestational age and birth weight as well as individual behaviour characteristics, engagement in physical activity and dietary habits $(8,11)$. How these confounders interact and whether they modify or enhance effect of other confounders still remains unexplored. Whereas several authors stress the importance of early origins (i.e. environmental causes) on childhood obesity, gaining of body fat mass and adult body composition, indicating at least 50\% leverage of environmental and lifestyle factors on the variation in body fat (30-32), the twin studies do not corroborate these findings (33-36). Consequently, a lack of association between duration of breastfeeding and anthropometric or body composition indices in adolescents, after adjustment for confounding factors, revealed more than $50 \%$ reduction in obesity among infants breastfed for three to five months, and also a linear decreasing trend in obesity along with longer duration of predominant breastfeeding compared to formula-fed individuals (37). Again, positive association between breastfeeding for two months or less with obesity in rural American teenagers disappeared after adjustment for sex, birthweight and socioeconomic status (14). Nevertheless, it is important to stress out a large number of studies reporting significant reduction in obesity among children predominantly breastfed for three or more months, independently of taking other confounding factors into consideration, and therefore questioning their impact and linkage with the effect of breastfeeding $(13,38-42)$. For instance, in a cross-sectional study on 33,768 children aged 6 to 14 years in the Czech Republic, there was a reduced prevalence of overweight and obesity in breastfed children, that was not confounded by socioeconomic status, parental BMI or maternal tobacco use (42), while the other research on a large number of German children at 5 to 6 years of age could not attribute the protective effect of breastfeeding against obesity to differences in social status or lifestyle (13). Also, a number of studies showed no consistent association between breastfeeding and obesity in children (12, 43-46), as well as in adolescents (25), even after adjustment for potentional confounders. However, our findings, although gained from a setting where lifestyle and socioeconomic status were homogeneous, after adjustment for potentional counfounders are in line with earlier published metaanalysis suggesting that longer duration of breastfeeding may be inversely associated with obesity (47). There are also data reporting that breastfeeding for $\geq 6$ months is associated with a reduction in risk of overweight and obesity (48), indicating that the most beneficial effect of breastfeeding occurs at about 6-8 months of age (10). Obviously, breastfeeding can affect and possibly change the positive correlation between being a heavy newborn and obesity in childhood and adulthood.

Though the studies focused on the association between the time of introduction of solids and adiposity at 7 years of age are scarce and results are ambiguous, there are reports in line with our findings indicating that children with early introduction of complementary food show greater fatness and weight gain than the ones who are introduced to complementary food later (10). Also, longer duration of breastfeeding is related to later introduction of complementary food and has protective effect on infancy weight gain. This difference in weight gain seems to disappear after the age of 18 months indicating that there is no additional benefit from delayed introduction of complementary food (16, 17), but it is unknown whether any effect subsists after childhood. Interestingly, there are reports of lower risk of fatness in children earlier introduced to solids (15). This discrepancy in results among studies may arise mostly from not considering body weight at the age when complementary foods were introduced since heavier infants are usually introduced to solids earlier (17), whereas there is also the influence of eating larger amounts of food among infants earlier introduced to solids. Nevertheless, unlike in our research where comparison of complementary food introduction was made at the age of 6 months, in other studies this borderline was mostly at 4 months or less (usually $<15$ weeks), presumably leading to contradicting results among studies. Namely, in the study on 847 preschool children, Huh et al. determined that among children who were never breastfed or were breastfed less than 4 months, the introduction of complementary food before the age of 4 months was associated with almost sixfold increased odds of obesity at the age of 3 (49). Also, this association was not explained by rapid early growth. Moreover, as opposed to our research, breastfeeding and timing of complementary food introduction were mostly explored as independent variables of later obesity, even though their combined effect is well known. Hence, those two determinants together implicate variances in later obesity as well as the appropriate adjustment for many of other confounders well known to be related to childhood obesity $(1,8,11)$. In addition, none of the studies, including ours, have explored an association between the weight gain and the age at which different food components (vegetable, fruit, egg, meat) were introduced to infants. Namely, several studies speculated on the role of high protein intake in early childhood obesity, but findings are still inconsistent (50). Unfortunately, the information on infant feeding was collected among 6-7 years old children and data on protein intake were insufficient.

The strength of this research lies in homogenous socioeconomic factors and uniform data acquisition, and control for a large number of confounding factors that may influence the breastfeeding effect on childhood obesity. Nevertheless, this study also has a number of limitations. Some dynamic factors that may affect fatty tissue foundation in children like obesity and pregnancy weight gain of the mother as well as weight gain of infants in the first months of life were not included in the analysis. Besides small sample size, residual or uncontrolled confounding factors can never be ruled out, but they are likely to explain the controversial literature results. Also, because information on infant feeding was obtained long after the time of actual breastfeeding, recall bias could also 
be an issue since not all information was available from children medical charts. However, generalization of our research results is limited because all of our examinees were Caucasians from middle-income families and parents with lower education levels.

\section{CONCLUSION}

Our findings suggest that breastfeeding for at least 3 months and postponed introduction of complementary food after 6 months of age have important role in lowering early childhood adiposity risk and are of great importance for planning preventive strategies to preclude further increases in the prevalence of overweight and obesity, given the relatively high prevalence of infants who are formula-fed or breastfed for less than 4 months. Nevertheless, further studies on large samples and long-term follow-up periods are needed to explore the independent determinants and confounders of obesity. Further research should focus on their interrelationship, in order to distinquish imperative, modifiable risk factors crucial for development of effective prevention strategies. Simultaneously, continued promotion and support of breastfeeding remain a leading public health priority.

\section{Acknowledgements}

We are thankful to all children and their families as well as to their paediatricians for collaboration and allowance for data insight.

\section{Conflict of Interests}

None declared

\section{Ethical Approval}

Ethical Committee of National Public Health Institute for Zagreb County approved the study protocol.

\section{REFERENCES}

1. Kosti RI, Panagiotakos DB. The epidemic of obesity in children and adolescents in the world. Cent Eur J Public Health. 2006 Dec;14(4):151-9.

2. Dietz WH. Critical periods in childhood for the development of obesity. Am J Clin Nutr. 1994 May;59(5):955-9.

3. Šekerija M, Ajduković D, Poljičanin T. Adolescent obesity-problem of today or the future. HČJZ. 2008;4:16. (In Croatian.)

4. Gopinath B, Baur LA, Burlutsky G, Robaei D, Mitchell P. Socio-economic, familial and perinatal factors associated with obesity in Sydney schoolchildren. J Paediatr Child Health. 2012 Jan;48(1):44-51.

5. Ravelli AC, van der Meulen JH, Osmond C, Barker DJ, Bleker OP. Infant feeding and adult glucose tolerance, lipid profile, blood pressure, and obesity. Arch Dis Child. 2000 Mar;82(3):248-52.

6. Hauner H, Rohrig K, Petruschke T. Effects of epidermal growth factor (EGF), platelet-derived growth factor (PDGF) and fibroblast growth factor (FGF) on human adipocyte development and function. Eur J Clin Invest. $1995 \mathrm{Feb} ; 25(2): 90-6$.

7. Koletzko B, von Kries R, Closa R, Escribano J, Scaglioni S, Giovannini M, et al; European Childhood Obesity Trial Study Group. Lower protein in infant formula is associated with lower weight up to age $2 \mathrm{y}$ : a randomized clinical trial. Am J Clin Nutr. 2009 Jun;89(6):1836-45.

8. Bergmann KE, Bergmann RL, von Kries R, Bohm O, Richter R, Dudenhausen JW, et al. Early determinants of childhood overweight and adiposity in a birth cohort study: role of breast-feeding. Int J Obes Relat Metab Disord. 2003 Feb;27(2):162-72.

9. Liese AD, Hirsch T, von Mutis E, Keil U, Leupold W, Weiland SK. Inverse association of overweight and breast-feeding in 9 to 10 year old children in Germany. Int J Obes Relat Metab Disord. 2001 Nov;25(11):1644-50.
10. Hediger ML, Overpeck MD, Kuczmarski RJ, Ruan WJ. Association between infant breast-feeding and overweight in young children. JAMA. 2001 May 16;285(19):2453-60.

11. Gillman MW, Rifas-Shiman SL, Camargo CA Jr, Berkey CS, Frazier AL, Rockett HR, et al. Risk of overweight among adolescents who were breastfed as infants. JAMA. 2001 May 16;285(19):2461-7.

12. Novaes JF, Lamouneir JA, Colosimo EA, Franceschini SC, Priore SE. Breastfeeding and obesity in Brazilian children. Eur J Public Health. 2012 Jun;22(3):383-9.

13. Von Kries R, Koletzko B, Sauerwald T, von Mutius E, Barnet D, Grunert V, et al. Breast feeding and obesity: cross sectional study. BMJ 1999;319:147-50.

14. Elliott KG, Kjolhede CL, Gournis E, Rasmussen KM. Duration of breastfeeding associated with obesity during adolescence. Obes Res. 1997 Nov;5(6):538-41.

15. Parsons TJ, Power C, Logan S, Summerbell CD. Childhood predictors of adult obesity; a systematic review. Int J Obes Relat Metab Disord. 1999 Nov;23 Suppl 8:S1-107.

16. Mehta KC, Specker BL, Bartholmey S, Giddens J, Ho ML. Trial on timing of introduction to solids and food type on infant growth. Pediatrics. 1998 Sep;102(3 Pt 1):569-73.

17. Morgan JB, Lucas A, Fewtrell MS. Does weaning influence growth and health up to 18 months? Arch Dis Child. 2004 Aug;89(8):728-33.

18. Weiss R, Caprio S. The Metabolic consequences of childhood obesity. Best Pract Res Clin Endocrinol Metab. 2005 Sep;19(3):405-19.

19. Wells JC, Hallal PC, Wright A, Singhal A, Victora CG. Fetal, infant and childhood growth: relationships with body composition in Brazilian boys aged 9 years. Int J Obes (Lond). 2005 Oct;29(10):1192-8.

20. Eriksson J, Forsen T, Tuomilehto J, Osmond C, Barker D. Size at birth, childhood growth and obesity in adult life. Int J Obes Relat Metab Disord. 2001 May;25(5):735-40.

21. Monteiro PO, Victora CG, Barros FC, Monteiro LM. Birth size, early childhood growth, and adolescent obesity in a Brazilian birth cohort. Int J Obes Relat Metab Disord. 2003 Oct;27(10):1274-82.

22. O'Callaghan MJ, Williams GM, Andersen MJ, Bor W, Najman JM. Prediction of obesity in children at 5 years: a cohort study. J Paediatr Child Health. 1997 Aug;33(4):311-6.

23. Dewey KG, Heinig MJ, Nommsen LA, Peerson JM, Lonnerdal B. Breast-fed infants are leaner than formula-fed infants at $1 \mathrm{y}$ of age: the DARLING study. Am J Clin Nutr. 1993 Feb;57(2):140-5.

24. Victora CG, Matijasevich A, Santos IS, Barros AJ, Horta BL, Barros FC. Breastfeeding and feeding patterns in three birth cohorts in Southern Brazil: trends and differentials. Cad Saude Publica. 2008;24 Suppl 3:S409-16.

25. Neutzling MB, Hallal PR, Araújo CL, Horta BL, Vieira Mde F, Menezes $\mathrm{AM}$, et al. Infant feeding and obesity at 11 years: Prospective birth cohort study. Int J Pediatr Obes. 2009;4(3):143-9.

26. Li L, Parson TJ, Power C. Breast-feeding and obesity in childhood: cross sectional study. BMJ. 2003 Oct 18;327(7420):904-5.

27. Tulldahl J, Pettersson K, Andersson SW, Hulthen L. Mode of infant feeding and achieved growth in adolescence: early feeding patterns in relation to growth and body composition in adolescence. Obes Res. 1999 Sep; 7(5):431-7.

28. Hedifer ML, Overpeck MD, Ruan WJ, Troendle JF. Early infant feeding and growth status of US-born infants and children aged 4-71 months: analyses from the third National Health and Nutrition Examination Survey, 1988-1994. Am J Clin Nutr. 2000 Jul;72(1):159-67.

29. Armstrong ME, Lambert MI, Sharwood KA, Lambert EV. Obesity and overweight in South African primary school children - the Health of the Nation Study. S Afr Med J. 2006 May;96(5):439-44.

30. Wake M, Hardy P, Canterford L, Sawyer M, Carlin JB. Overweight, obesity and girth of Australian preschoolers: prevalence and socio-economic correlates. Int J Obes (Lond). 2007 Jul;31(7):1044-51.

31. Wang MC, Crespi CM. The influence of childhood and adolescent environmental exposure to a westernized environment on the relation between body mass index and adiposity in young Asian American women.Am J Clin Nutr. 2011 May;93(5):1168S-74S.

32. Stettler N, Tershakovec AM, Zemel BS, Leonard MB, Boston RC, Katz $\mathrm{SH}$, et al. Early risk factors for increased adiposity: a cohort study of african american subjects followed from birth to young adulthood. Am J Clin Nutr. 2000 Aug;72(2):378-83.

33. Hakala P, Rissanen A, Koskenvuo M, Kaprio J, RoÈnnemaa T. Environmental factors in the development of obesity in identical twins. Int J Obes Relat Metab Disord. 1999 Jul;23(7):746-53.

34. Stunkard AJ, Harris JR, Pedersen NL, McClearn GE. The bodymass index of twins who have been reared apart. N Engl J Med. 1990 May 24;322(21):1483-7. 
35. Vogler GP, Sorensen TIA, Stunkard AJ, Srinivasan MR, Rao DC. Influences of genes and shared family environment on adultbody mass index assessed in an adoption study by comprehensive path model. Int J Obes Relat Metab Disord. 1995 Jan;19(1):40-5.

36. Allison DB, Kaprio J, Korkeila M, Koskenvuo M, Neale M, Hayakawa $\mathrm{K}$. The heritability of body mass index among an international sample of monozygotic twins reared apart. Int J Obes Relat Metab Disord. 1996 Jun;20(6):501-6.

37. Victora CG, Barros F, Lima RC, Horta BL, Wells J. Anthropometry and body composition of 18 year old men according to duration of breast feeding: birth cohort study from Brazil. BMJ. 2003 Oct 18;327(7420):901.

38. Mayer-Davis EJ, Rifas-Shiman SL, Zhou L, Hu FB, Colditz GA, Gillman MW. Breast-feeding and risk for childhood obesity: does maternal diabetes or obesity status matter? Diabetes Care. 2006 Oct;29(10):2231-7.

39. Lamb MM, Dabelea D, Yin X, Ogden LG, Klingensmith GJ, Rewers M, et al. Early-life predictors of higher body mass index in healthy children. Ann Nutr Metab. 2010;56(1):16-22. Erratum in: Ann Nutr Metab. 2011;59(2-4):78.

40. Lamerz A, Kuepper-Nybelen J, Wehle C, Bruning N, Trost-Brinkhues G, Brenner H, et al. Social class, parental education, and obesity prevalence in a study of six-year-old children in Germany. Int J Obes (Lond). 2005 Apr;29(4):373.

41. Harder T, Bergmann R, Kallischnigg G, Plagemann A. Duration of breastfeeding and risk of overweight: a meta-analysis. Am J Epidemiol. 2005 Sep 1;162(5):397-403.

42. Toschke AM, Vignerova J, Lhotska L, Osanckova K, Koletzko B, von Kries R. Overweight and obesity an 6- to 14 year old Czech children in 1991 protective effect of breast-feeding. J Pediatr. 2002 Dec;141(6):764-9.
43. Kwok MK, Schooling CM, Lam TH, Leung GM. Does breastfeeding protect against childhood overweight? Hong Kong's 'Children of 1997 birth cohort. Int J Epidemiol. 2010 Feb;39(1):297-305.

44. Reilly JJ, Armstrong J, Dorosty AR, Emmet PM, Ness A, Rogers IS, et al. Early life risk factors for obesity in childhood: cohort study. BMJ. 2005 Jun 11;330(7504):1357.

45. Parsons TJ, Power C, Manor O. Infant feeding and obesity through the lifecourse. Arch Dis Child. 2003 Sep;88(9):793-4.

46. Poulton R, Williams S. Breastfeeding and risk of overweight. JAMA 2001 Sep 26;286(12):1449-50.

47. Owen CG, Martin RM, Whincup PH, Smith GD, Cook DG. Effect of infant feeding on the risk of obesity across the life course: a quantitative review of published evidence. Pediatrics. 2005 May;115(5):1367-77.

48. Toschke AM, Martin RM, von Kries R, Wells J, Smith GD, Ness AR Infant feeding method and obesity: body mass index and dual-energy X-ray absorptiometry measurements at 9-10 y of age from the Avon Longitudinal Study of Parents and Children (ALSPAC). Am J Clin Nutr. 2007 Jun;85(6):1578-85.

49. Huh SY, Rifas-Shiman SL, Taveras EM, Oken E, Gillman MW. Timing of solid food introduction and risk of obesity in preschool-aged children. Pediatrics. 2011 Mar;127(3):e544-51.

50. Gunther AL, Buyken AE, Kroke A. Protein intake during the period of complementary feeding and early childhood and the association with body mass index and percentage body fat at $7 \mathrm{y}$ of age. Am J Clin Nutr. 2007 Jun;85(6):1626-33

Received September 12, 2013 Accepted in revised form October 22, 2014 